\title{
INVISIBILIDADE SOCIAL E PRODUÇÃO DO ESPAÇO SUBORDINADO EM BELÉM (PA)
}

\author{
SOCIAL INVISIBILITY AND PRODUCTION OF SUBORDINATED SPACE IN BELÉM (PA)
}

\author{
Ana Cláudia Duarte Cardoso* \\ Thales Barroso Miranda**
}

\section{RESUMO}

As dificuldades históricas de aproximação entre a lógica ambiental e o planejamento urbano favoreceram práticas de exclusão socioambiental na expansão urbana de Belém, na medida em que novos arranjos espaciais e sociais 'naturalizaram' mudanças ambientais que afetam grupos sociais de menor renda oriundos da várzea (caboclos e ribeirinhos). A releitura da expansão de Belém revela uma progressiva desarticulação entre o homem, seu modo de vida e a base biofísica na produção da cidade; em que a supressão de vegetação, o adensamento construtivo e a localização dos rios contaminados com lançamentos de esgoto, inviabilizaram práticas tradicionais e contribuíram para alterações no microclima urbano. Os dados empíricos indicam que na periferia metropolitana de Belém coexistem grupos sociais, desde os que dependem da natureza (agricultores e extrativistas urbanos), até típicos moradores da periferia da cidade capitalista, um ponto cego para as políticas urbanas que tendem a homogeneizar o espaço sem atenção ao potencial de soluções que a diversidade oferece aos desafios da exclusão social e do risco ambiental. Cartografias da ocorrência da água e da vegetação, análises morfológicas e pesquisas de campo procuram revelar os potenciais positivos da resistência das velhas práticas para Belém e para a cidade brasileira em geral, mas principalmente para as cidades amazônicas, que ainda tomam a metrópole como referência de "civilização". Palavras-chave: Belém (PA). Cidades Amazônicas. Exclusão socioambiental. Alterações Climáticas.

\section{ABSTRACT}

The historical difficulties of integrating environmental logic and urban planning have upheld practices of social and environmental exclusion in the urban expansion of Belém, to the extent that new spatial and social arrangements have 'naturalized' environmental changes that affect low-income social groups from the floodplains (caboclos and riparian). By re-examining the expansion of Belém we discover in the production of the city a progressive disarticulation of man, his ways of life and biophysical bases, where the suppression of vegetation, constructive densification and the location of rivers contaminated

\footnotetext{
* Universidade Federal do Pará. Programa de Pós-Graduação em Arquitetura e Urbanismo.

Avenida Augusto Corrêa, 01, 66075-110, Cidade Universitária, Setor Profissional, Faculdade de Arquitetura e Urbanismo, Laboratório Cidades da Amazônia (LABCAM/UFPA), Belém, PA, Brasil Lattes: http://lattes.cnpq.br/3138101153535395

Orcid: https://orcid.org/0000-0002-1866-453X.

E-mail: aclaudiacardoso@gmail.com

** Universidade Federal do Pará. Programa de Pós-Graduação em Arquitetura e Urbanismo. Avenida Augusto Corrêa, 01, 66075-110, Cidade Universitária, Setor Profissional, Faculdade de Arquitetura e Urbanismo, Laboratório Cidades da Amazônia (LABCAM/UFPA), Belém, PA, Brasil.

Lattes: http://lattes.cnpq.br/2983400210216778

Orcid: https://orcid.org/0000-0002-0262-8075

E-mail: thalesbmiranda@gmail.com
} 
by sewage outlets have rendered traditional practices unfeasible and contributed to changes in the urban microclimate. Empirical data indicate that in the metropolitan periphery there are coexisting social groups, ranging from those who depend on nature (urban farmers and extractivists) to the characteristic inhabitants of the periphery in a capitalist city, a blind spot for urban policies, which tend to homogenize space and pays no heed to the potential of solutions that this diversity may offer to the challenges of social exclusion and environmental risk. Cartographies of the occurrence of water and vegetation, morphological analyses and field research seek to reveal the positive potentials of the resistance of old practices for Belém and for Brazilian cities in general, although especially for Amazonian cities, which still regard the metropolis as a reference of 'civilization'.

Keywords: Belém (PA). Amazonian cities. Socio-environmental exclusion. Climate change.

\section{INTRODUÇÃO}

Belém é metrópole há 400 anos. Muito antes de ocorrer uma total identificação da era industrial com o urbano metropolitano, a cidade de Belém já polarizava vasta região, conectava-se ao sistema econômico global por meio da comercialização em larga escala de produtos extrativos (cacau, fumo, especiarias, borracha, juta, etc.), e desenvolvia uma capacidade de articulação de dois universos distintos: o urbano industrial europeu e o ribeirinho amazônico (CARDOSO et al 2015). A ocupação da cidade refletiu essas duas faces na forma como os terrenos mais altos foram ocupados, pela quadrícula pré-definida oficialmente (plano de alinhamento de Nina Ribeiro), e as áreas baixas e de várzea, foram sendo ocupadas por usos menos nobres (estabelecimentos industriais no bairro Reduto; cemitérios, hospitais e asilos no bairro Guamá; vacarias e espaços de hortas, nos bairros da Cremação e Terra Firme) (CARDOSO; RODRÍGUES, 1990; ABELÉM, 1988; TRINDADE JR., 1988, MOURÃO, 1987).

Ao longo de sua existência, a cidade sofreu várias modernizações que a prepararam para melhor exercer sua função de metrópole: a) em meados do século XVIII houve a modernização promovida pelo Marquês de Pombal para transformá-la em capital político-administrativa de toda a região amazônica (CORREA, 1987); b) durante o ciclo da borracha houve a introdução de novas tecnologias (redes técnicas que viabilizaram serviços semelhantes aos das cidades europeias - transporte, energia elétrica; ou equipamentos - mercados, teatros), controle urbanístico para edificações das áreas nobres, introdução de praças e delimitação de parques (atuais parque zoobotânico do Museu Paraense Emílio Goeldi e Bosque Rodrigues Alves), e a culminância da implantação de uma ferrovia ligando Belém à Bragança (CASTRO, 2010; SARGES, 2004; CORREA, 1987); c) durante o governo militar grandes ações de saneamento iniciaram a transformação da várzea do lgarapé das Almas, fortalecendo a perspectiva da macrodrenagem, aterro e canalização dos rios (CARDOSO; VENTURA NETO, 2013); e concluiu-se a substituição da ferrovia por uma rodovia que se tornou o principal eixo de expansão metropolitana. Nessa época a produção habitacional financiada pelo Banco Nacional de Habitação (BNH), precipitou a conurbação com Ananindeva e viabilizou a formalização da Região Metropolitana de Belém (RMB) no decreto que estabeleceu as demais Regiões Metropolitanas brasileiras (BRASIL, 1973). 
O período da integração nacional articulou a região espacial e economicamente ao restante do país, reduzindo a importância de Belém e fortalecendo a metrópole de Manaus, e todas as demais capitais estaduais como polos regionais (CORREA, 1987). Havia uma leitura de insuficiência sempre que cidades de regiões industrializadas eram tomadas como parâmetro de comparação em relação às cidades da região; a economia de Belém sempre dependeu de serviços vinculados às atividades produtivas que efetivamente aconteciam no universo rural. E se o rural manifestava a "vocação" do extrativismo (mineral, madeireiro, produção de energia) (TAVARES, 1986), também registrava o padrão milenar de dispersão da população no território (HECKENBERGER, 2000) que responde à tradição de articulação entre pessoas, natureza e biodiversidade.

A narrativa produzida por esses processos de modernização mantinha a face ribeirinha e amazônica das cidades, e particularmente de Belém, como um ponto cego. Na medida em que a mancha urbana cresceu e se estabeleceram as práticas sociopolíticas típicas das elites urbanas brasileiras - cosmopolitismo, rentismo e patrimonialismo (MARICATO, 2015; VILLAÇA, 1998), maior se tornou a contradição entre a concepção de cidade dirigida para as áreas altas e para as áreas baixas (as várzeas, chamadas localmente de baixadas).

Nessa altura, Belém passou a ser compreendida como uma cidade inserida na fase moderno industrial', e sujeita a processos de periferização, segregação, desarticulação, fragmentação, etc. (MARICATO, 2015; RIBEIRO, 2004; VILLAÇA, 1998), sem o reconhecimento da coexistência de modos de vida (moderno e amazônico tradicional), e pior ainda, sem a compreensão da importância da natureza e da base biofísica para a sobrevivência das práticas que historicamente foram bem sucedidas na região, mas que foram progressivamente associadas ao atraso, não reconhecidas pelas políticas públicas implementadas nas sucessivas ondas de modernização.

Neste artigo procura-se explorar o quanto as manifestações da periferização podem ser associadas às formas de produção a partir da natureza (agricultura, pesca, coleta, contato social e lúdico como o rio) e expressar o potencial de resistência de modos de vida da região às colonizações sofridas, que assumem maior relevância na medida em que avança a crise ambiental e o consumo no planeta.

O texto apoia-se em documentos, observações de campo e cartografias para associar padrões de uso e ocupação, polvição dos rios urbanos, involução do verde, o aumento de temperatura e a trajetória de mudança de agricultores urbanos (oriundos do interior do estado) na porção continental da mancha urbana metropolitana.

A narrativa oferecida também destaca o padrão histórico de assimilação de soluções e paradigmas externos, pautados na tecnologia, escala, e institucionalidade de cidades industriais, e oferece um olhar alternativo, que revê os problemas da

Segundo Lefebvre (1999), a fase moderno-industrial teve início após a transposição do ponto de inflexão da evolução da humanidade da sociedade agrária para a sociedade industrial. Nesta fase, a degradação da natureza e a dominação social são práticas comuns e onde acontece a dissolução da cidade (por implosão de áreas consolidadas e explosão de usos urbanos pelo território anteriormente rural) com a formação de um tecido urbano estendido, que articula áreas centrais a periferias cada vez mais distantes. 
metrópole periférica ao capitalismo global, em busca de formulações próprias para uma agenda de desenvolvimento, mais compatível tanto com as demandas contemporâneas de adaptação das cidades ao contexto de mudanças climáticas face à sua capacidade de afetar mais severamente os mais pobres (BUENO, 2013), quanto com o agravamento da exclusão social observado após o avanço da financeirização da produção da cidade e da disputa por terras rurais pelo agronegócio (LIMONAD, 2013).

\section{COEXISTÊNCIA DE DINÂMICAS SOCIOECONÔMICAS PARA A FORMAÇÃO DA METRÓPOLE DE BELÉM}

O espaço urbano de Belém foi estruturado, ao longo dos seus 400 anos, com base no hibridismo entre duas lógicas espaciais que foram alimentadas pelo dinamismo extrativista da região. De um lado, a lógica moderna (industrial) estruturou o território em momentos de auge de exportações e de desempenho econômico - como ocorrido no ciclo da borracha (1850-1920), sob o comando de elites regionais (CARDOSO et al, 2015). Essa articulação global pautou e viabilizou os melhoramentos urbanísticos e padrões de urbanização de inspiração europeia, existentes nas terras altas do centro metropolitano de Belém. Por outro lado, a lógica de produção espacial tradicional foi seguida na ocupação das áreas de várzea, ocupadas por migrantes que mantiveram maior interação com a natureza por meio dos cursos d'água, dos quintais e das áreas vegetadas nas atividades cotidianas - econômicas e recreativas, produzindo espaços não planejados, sem segurança de posse, que quando adensados passaram a ser reconhecidos como assentamentos informais; originalmente, nestas áreas a interação das pessoas com a terra e a natureza cumpria funções socioeconômicas e ambientais (ex.: agricultura urbana, extrativismo, lazer).

O agravamento dos conflitos rurais e a reestruturação produtiva do campo intensificaram o êxodo rural e ressignificaram a ocupação das várzeas como periferias urbanas modernas (TRINDADE JR, 1998), sujeitas a adensamento progressivo, face à falta de regras, de parâmetros e à força com que o paradigma industrial foi assimilado na produção da cidade. As várzeas próximas ao centro eram a periferia próxima e a fronteira entre Belém e Ananindeua, em produção a partir da implantação de conjuntos habitacionais, tornava-se a periferia distante.

O padrão de segregação das cidades brasileiras foi estabelecido em Belém a partir das condições de ocupação do sítio físico, as terras altas eram locais de moradia das classes privilegiadas e as terras baixas (baixadas) eram o espaço que restava para a absorção da população migrante. Na área nobre, o planejamento oficial proveu praças, parques, ruas, e manteve ruas e lotes regulares, atendendo a uma expectativa de modo de vida traduzida no preço mais elevado da terra. Nas baixadas, a falta de fiscalização, justificada pela ocupação irregular da terra, manteve as diretrizes espa- 
ciais até onde o sítio físico permitiu, diferenciando bairros, que após décadas de um processo de aterro e melhoramento gradual (ou de consolidação) contam com maior ou menor grau de facilidade de incorporação ao mercado formal de terras, na medida em que a metrópole se expande e a proximidade das áreas nobres começa a gerar expectativas de ganho imobiliário compensatórios. $\bigcirc$ problema da disputa pela terra urbana (MARICATO, 2015; VILLAÇA, 1998) favoreceu a homogeneização do território da cidade, e a presunção de homogeneidade de necessidades da população.

$\mathrm{Na}$ prática, os ciclos de ocupação das várzeas da Primeira Légua de Belém, iniciados nos anos 1960, ofereceram acesso à cidade aos migrantes da zona rural e garantiram uma transição longa o bastante para que essa população fosse assimilada como mão de obra nos setores de comércio e serviço, formal e informal. Cardoso (2002) apresenta evidências de que essa ocupação foi positiva para esses grupos sociais, na medida em que permitiu sua inclusão na cidade, após períodos de consolidação que dependiam de volume populacional, barganha entre ações de meIhoramentos e votos, convergência de interesses, mas que causavam o apagamento da natureza e do tipo de relacionamento anterior que os migrantes mantinham com a base biofísica. $\bigcirc$ aterro, o asfalto e o aproveitamento de qualquer área disponível para edificação tornaram as ocupações de várzea variantes das favelas das metrópoles industriais brasileiras que, para o planejamento oficial, precisavam ser erradicadas e ter sua população direcionada para os conjuntos habitacionais.

Como ilustração desse processo, Miranda e Cardoso (2017) constataram que antes do adensamento, o bairro da Terra Firme, em Belém, era local de produção agrícola de pequenos produtores que plantavam para a subsistência e vendiam os excedentes à comunidade local e às principais feiras da cidade na época; com o aumento populacional, a insegurança e a pressão exercida pelos novos moradores em busca de áreas de produção de moradia, esses produtores se deslocaram para outras regiões da RMB, nos municípios de Ananindeua, Benevides e Santa lzabel do Pará. $\bigcirc$ adensamento das ocupações de área de várzea, também ocorreu na área de expansão de Belém (nos atuais bairros da Marambaia, Paracuri, Mata Fome, Taboquinha), até que o modelo hegemônico de produção habitacional difundido na área de expansão de Belém (conjuntos habitacionais, loteamentos e condomínios fechados) precisasse dispor das áreas de várzea para viabilizar seus empreendimentos.

Contudo, a eliminação de áreas de várzea da cidade não foi acompanhada pela absorção dos migrantes em outras atividades produtivas, nem pela provisão de espaços de acesso público que viabilizassem as práticas de sociabilidade e lazer da população local, ou compensassem a crescente impermeabilização do solo. $\mathrm{Na}$ prática houve exclusão desses grupos sociais pelo acesso seletivo à terra dotada de infraestrutura, mas também pela eliminação de recursos como água limpa, terra para uso coletivo, e pela derradeira imposição de um modo de vida em que o trabalhador precisa de uma unidade habitacional cujo lote pressupõe apenas a necessidade de 
moradia, objeto da produção em massa e concentradora de população com necessidades semelhantes de oportunidades de trabalho e geração de renda, conforme será detalhado na sessão seguinte. Novos ciclos foram abertos a partir da transferência de parte dessa população para outras áreas mais afastadas e da chegada de novos migrantes do interior do estado, para novas localidades, que agora reproduzem o mesmo processo em escala metropolitana (MIRANDA; CARDOSO, 2017).

Uma evidência disso foi a evolução da proporção de agricultores nas tipologias ocupacionais adotadas por Lima et $(2015)^{2}$, espacializadas por área de ponderação da Região Metropolitana de Belém, de que houve uma redução da representação de agricultores de 1\% em 2000 para 0,5\% em 2010 nas áreas marcadas na figuras 1 e 2 como tipos médio inferiores, inseridas no centro metropolitano; o percentual dessa ocupação permaneceu relativamente estável (evoluiu de 1,84\% para 2,26\% de 2000 para 2010) nas áreas continentais que compunham as bordas da mancha urbana, incluindo áreas ambientalmente protegidas em 2000 e excluindo tais áreas em 2010 (áreas marcadas como tipo popular médio nas figuras 1 e 2), de menor acessibilidade ou de várzea. Ampliando o gradiente, observa-se que em 2000 a área correspondente às ilhas e aos municípios, que na época eram a periferia metropolitana mais distante, concentravam $12,86 \%$ de agricultores, proporção que foi reduzida para 9,49\% em 2010, abrangendo extensão mais restrita às ilhas, áreas protegidas, e aos núcleos rurais dos municípios que compunham a malha metropolitana que era contínua naquela época (correspondente ao tipo popular inferior nas figuras 1 e 2), onde há condições mais favoráveis para a prática de modos de vida tradicionais. Neste mesmo intervalo de tempo observou-se uma queda de cerca de $50 \%$ no percentual de agricultores (de 53,2\% para 23,25\%) no tipo popular agrícola, que também fez um movimento de deslocamento de Benevides para Santa Izabel do Pará e Santa Bárbara do Pará, e manteve-se estável em Castanhal (LIMA et al, 2015:156-158). Tal padrão de evolução da localização de grupos populares (Popular Agrícola, Popular Inferior, Popular Médio) entre 2000 e 2010, enfatiza a migração das baixadas de Belém para as áreas de Ananindeua e Benevides, e para municípios mais afastados, como Santa Bárbara do Pará e Santa lzabel do Pará (ver figuras 1 e 2). Neste último município, o setor primário, especialmente agricultura, é responsável por $25 \%$ do PIB (IBGE, 2014).

2 O estudo de Lima et al (2015) baseia-se em análise fatorial estratifica em categorias sócio-ocupacionais os ocupados o universo de pessoas ocupadas por área de ponderação. Essa metodologia foi aplicada às metrópoles brasileiras investigadas pela Rede Observatório das Metrópoles para permitir a comparação das mesmas e a identificação de tendências socioespaciais. A ocorrência dos agricultores é assumida como evidência quantitativa, dada à carência de bases de dados capazes de detectar a presença de agricultores e extrativistas em meio urbano e metropolitano. 


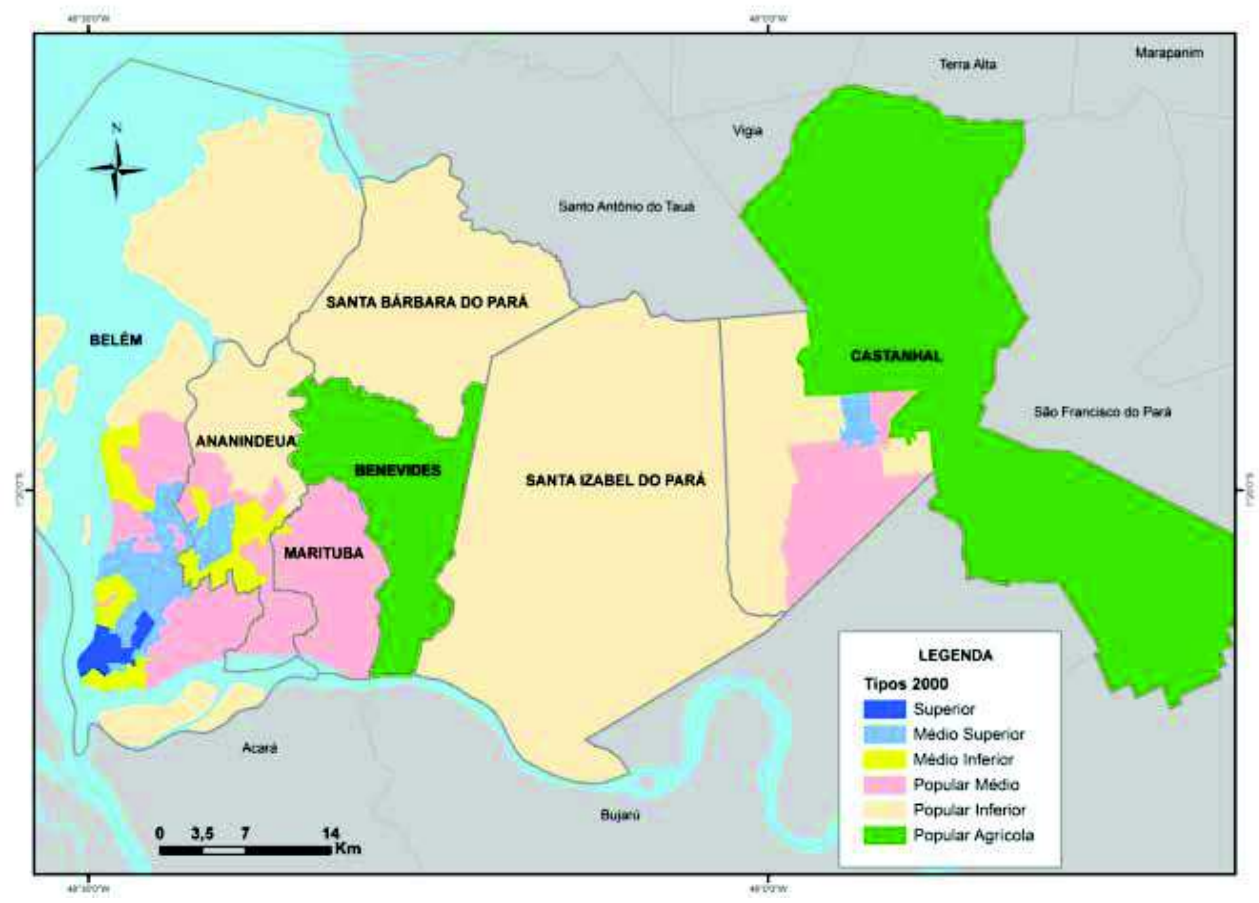

Figura 1 Mapa de distribuição das Categorias Sócio Ocupacionais na RMB para os anos 2000. Fonte: LIMA et al (2015, p. 156).

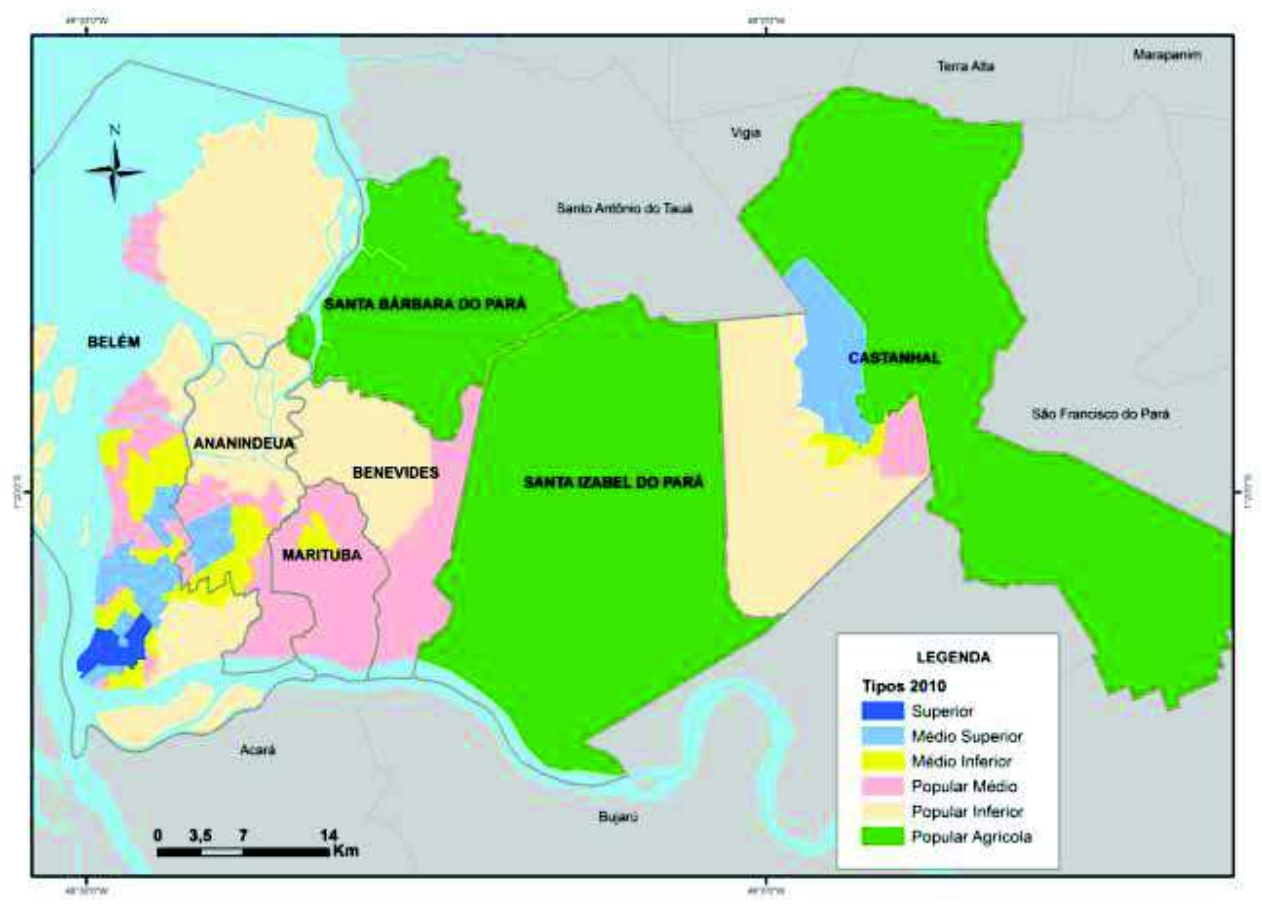

Figura 2 Mapa de distribuição das Categorias Sócio Ocupacionais na RMB para o ano de 2010 Fonte: LIMA et al (2015, p. 158). 
A figura 3 ilustra a movimentação de grupos de agricultores urbanos investigada na pesquisa de campo (MIRANDA; CARDOSO, 2017) que apesar de mudanças de localização continuam ativos, com localização em relação à mancha urbana sempre associada à disponibilidade de terra, água e biodiversidade. Sua permanência está associada ao mercado existente para seus produtos, ainda que exista grande relutância nas famílias em relação à continuidade das atividades. Dentre os entrevistados observou-se baixa autoestima, desvalorização do saber sobre práticas agrícolas, insegurança e desejo de que as gerações mais jovens trabalhem no setor de comércio e serviço, em funções que não requerem qualificação, mas que viabilizam a carteira assinada.

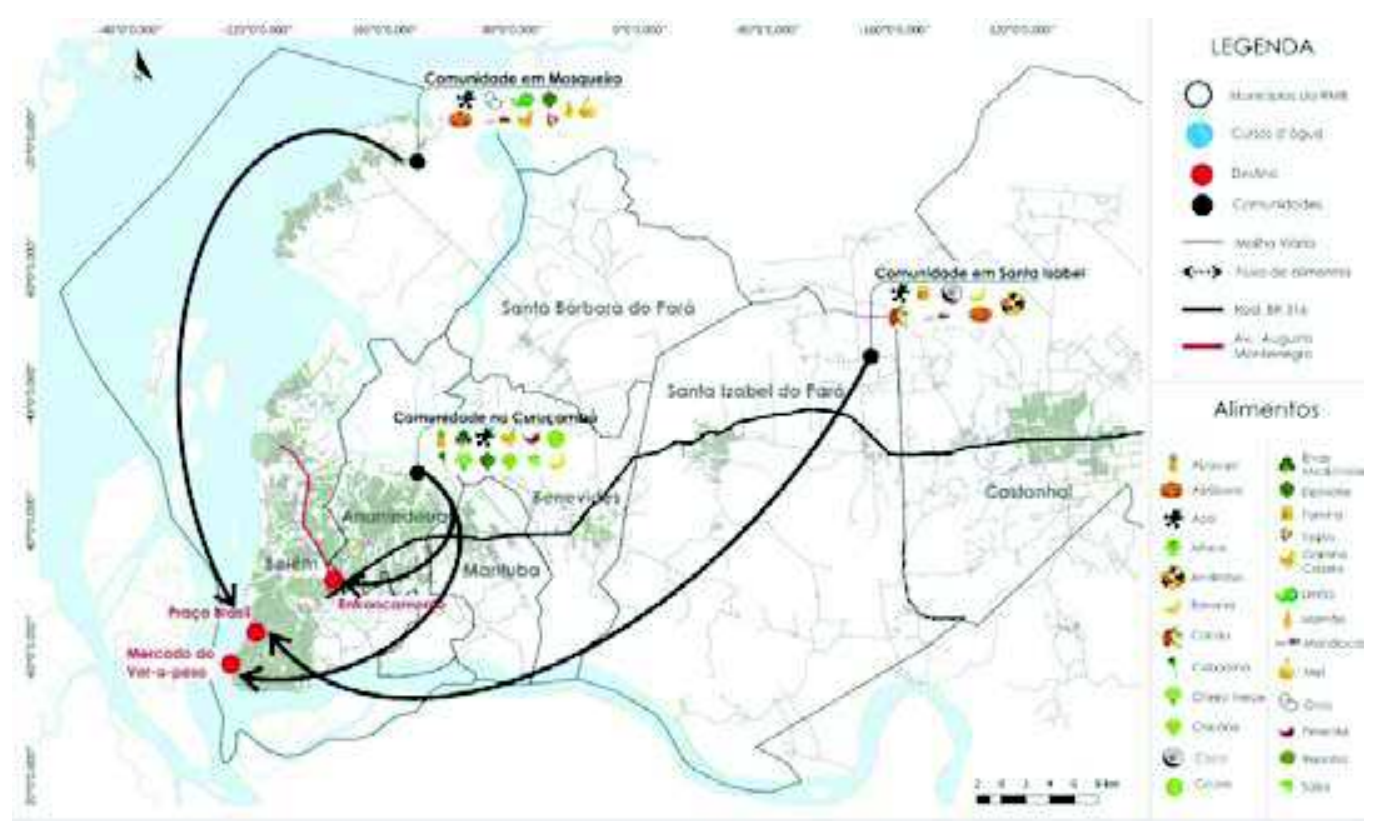

Figura 3 Mapa de distribuição dos alimentos produzidos em comunidades estudadas na Região Metropolitana de Belém.

Fonte: Miranda e Cardoso (2017, p. 11).

Na comunidade do Curuçambá, no município de Ananindeua, as hortaliças são compradas por atravessadores (agentes de comercialização que compram as mercadorias e repassam para outros compradores) para revenda nos Mercados públicos do Ver-o-Peso e do Entroncamento, este último é o ponto de concentração de onde vários feirantes partem para abastecer as feiras da Região Metropolitana de Belém.

Enquanto que na llha de Mosqueiro, em Belém e no município de Santa Izabel do Pará, o processo se dá de maneira distinta. Os produtos orgânicos dessas comunidades são comercializados em feiras quinzenais no centro de Belém (que se alternam nas Praças Brasil e Batista Campos) e entregues aos consumidores. Há também a possibilidade de encomenda de "paneiros" através de grupos da agroecologia, como - Grupo para Consumo Agroecológico (GRUCA). 
O padrão de atividade híbrida (urbana/rural) ainda não foi reconhecido pela agenda de planejamento oficial, apesar da carência de empregos industriais em Belém. A cidade sempre esteve sujeita à política urbana e metropolitana, que a partir dos anos 1970, assumiu como regra a descentralização produtiva do sudeste para outras capitais brasileiras - como ocorrido em Belo Horizonte, Curitiba e Porto Alegre (TONUCCI FILHO et al, 2015). Em Belém, o poder da indústria foi sentido através do impacto das grandes obras de infraestrutura logística e também da produção habitacional, em várias gerações de empreendimento públicos (conjuntos habitacionais) e privados (loteamentos, empreendimentos imobiliários) que pressupunham um modo de vida diferente daquele que os grupos sociais de menor poder aquisitivo, a que se dirigiam efetivamente tais empreendimentos, praticavam (SOUZA, 2016; SANTOS; CARDOSO, 2015).

A metrópole Belém, sempre foi uma cidade terciária, sustentada por atividades de serviço e comércio, apoiada pelos ciclos de extração de produtos da região. Belém conta com mais da metade do seu território resultante de produção informal (IBGE, 2010) e a inserção da região na divisão social do trabalho brasileira não modernizou todas as relações de trabalho. $\bigcirc$ sistema não compreendeu que as pessoas expulsas do campo sobrevivem a partir do trabalho na terra, rios e floresta e que as cidades amazônicas eram adaptadas para absorver essa população nas feiras e mercados. Tampouco que por meio dessa lógica tradicional ainda se viabiliza grande parte do consumo de alimentos, da reprodução do saber e da economia popular na Amazônia.

Os efeitos da exploração industrial de recursos naturais na região foram sentidos na RMB por meio da concentração de atividades comerciais e financeiras, e a nova escala de aglomeração metropolitana ampliou o mercado dos produtos (COSTA; FERNANDES, 2016) mantendo a vitalidade de feiras e mercados (ver figuras 4 e 5), e a demanda por mercadorias agrícolas de produção familiar ou extrativista tais como o açaí, cupuaçu, graviola, farinha de mandioca, dentre outros, associados historicamente, ao sustento das famílias ribeirinhas amazônicas, e incorporados na produção agrícola que acontece dentro da RMB (COSTA; FERNANDES, 2016; MIRANDA; CARDOSO, 2017).

Além dos aspectos sociais e econômicos da desarticulação entre as políticas urbanas e as práticas de sobrevivência das camadas populares, é preciso destacar que a homogeneização da paisagem da cidade, segundo as determinações do interesse imobiliário, também teria desdobramentos ambientais importantes, sob os aspectos físicos e climáticos, que tendem a ser intensificados pelo contexto de aquecimento global. Ao expulsar a população que depende da natureza para seu sustento, a produção planejada da cidade tem reduzido as condições de permeabilidade do solo, a distribuição das massas vegetais, a área de movimentação dos rios sobre suas várzeas no decorrer de seus ciclos naturais (tempo médio de cinquenta anos), poten cializando fenômenos como ondas de calor, inundação e alagamentos (MOREIRA, 


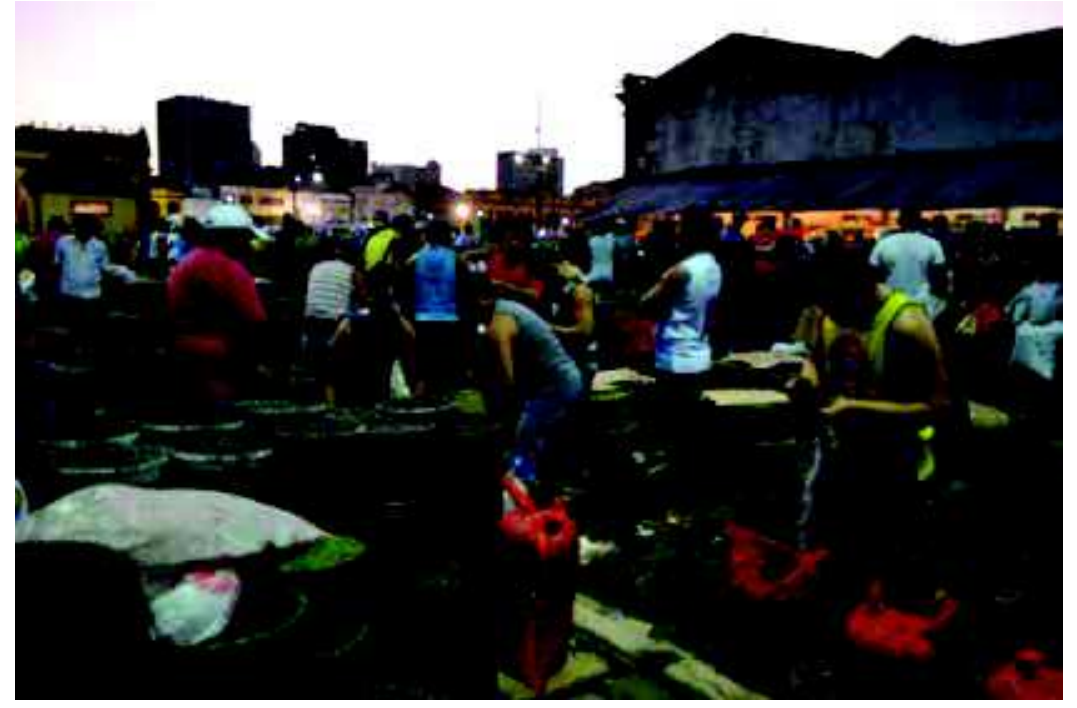

Figura 4 Foto da Feira do Açaí ao amanhecer, Belém. Foto: Taynara Gomes, 2015.

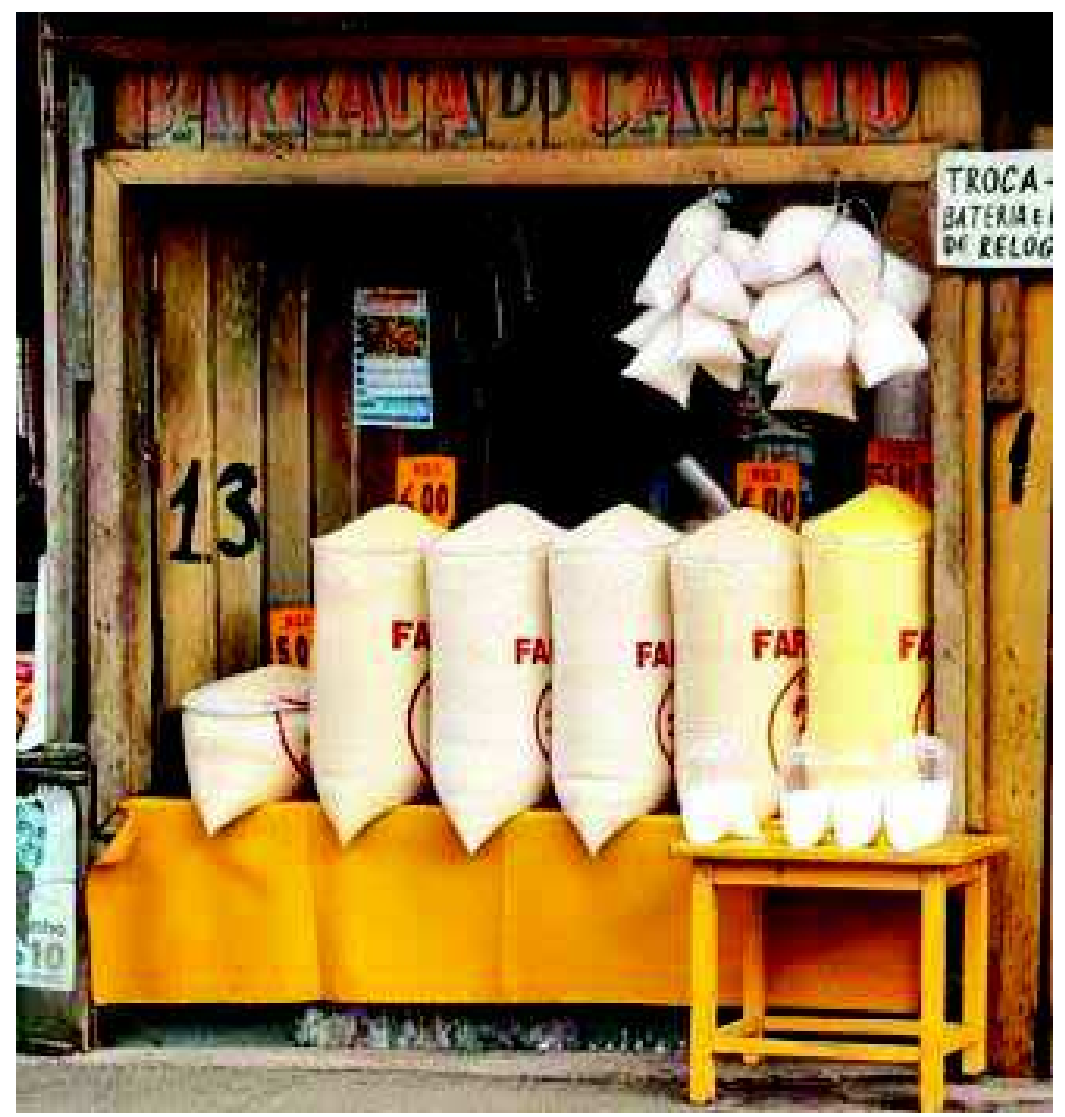

Figura 5 Foto de uma barraca de farinha de mandioca na Feira do Porto Palha, Belém. Foto: Monique Bentes, 2017. 
2018). Sob esse ponto de vista, o impacto desse tipo de urbanização promete ser de magnitude muito superior para a gestão metropolitana do que os ganhos imediatos obtidos pelos agentes sociais que o validam e fomentam. Quem "pagará a conta" no futuro?

\section{TRAJETÓRIAS SOCIOAMBIENTAIS E RESISTÊNCIAS}

Apesar da sua localização em região estuarina da planície amazônica, Belém e os demais municípios da região metropolitana seguem o padrão contemporâneo de urbanização de regiões periféricas, onde as determinações econômicas sobrepujam as determinações do meio ambiente, e desconsideram o saber ancestral dos habitantes das várzeas. Segundo Bueno (2013) as práticas urbanas do modelo hegemônico contribuem para perda de cobertura vegetal e polvição dos rios urbanos, o que favorece alterações do ecossistema, a intensificação de ilhas de calor e eventos climáticos imprevisíveis. Entre 2006 e 2016, as alterações de uso e ocupação do solo realizadas na área de expansão de Belém reduziram em 10\% a permeabilidade de duas de suas sete bacias hidrográficas; e a Bacia do Una já está com menos de $20 \%$ de sua área permeável; ressalte-se que, segundo Araujo et al (2008), 20\% é o mínimo tolerável de solo permeável para as bacias hidrográficas, o que deveria ser respeitado a risca em uma cidade plana como Belém (CARDOSO; MIRANDA; COSTA, 2016).

A figura 6 mostra um mapa de gradiente da cobertura vegetal, e a sua relação com os rios urbanos contidos em recortes selecionados como representativos dos diferentes períodos de urbanização da cidade para aproximar aspectos urbanísticos e ambientais. A construção do mapa de cobertura vegetal foi obtida a partir de imagens de satélite RapidEye disponibilizadas gratuitamente pelo Geo Catálogo do Ministério do Meio Ambiente (MMA) (http://geocatalogo.mma.gov.br/), para o ano de 2015. Utilizou-se as bandas espectrais 4 (Red Edge 690-730nm) e 5 (Infravermelho próximo 760-850 nm) para gerar o Índice de Vegetação da Diferença Normalizada (NDVI). Segundo Gitelson \& Merzlyak (1994) a extração das áreas verdes consiste em uma equação entre as bandas do Red Edge e do infravermelho próximo, como demonstrado na equação 1 abaixo:

$$
N D V I=\frac{(\mathrm{NIR}-\mathrm{RE})}{(\mathrm{NIR}+\mathrm{RE})}
$$

NIR corresponde ao valor da reflectância da banda no Infravermelho próximo e RE corresponde ao valor de reflectância da banda no Red Edge. Essa investigação apoia-se no estudo de Souza et al (2015) que demonstra que a utilização da banda Red Edge consegue distinguir diferentes tipos de clorofila e produzir mais transmitância das folhas, permitindo um mapeamento de áreas verdes mais refinado. 


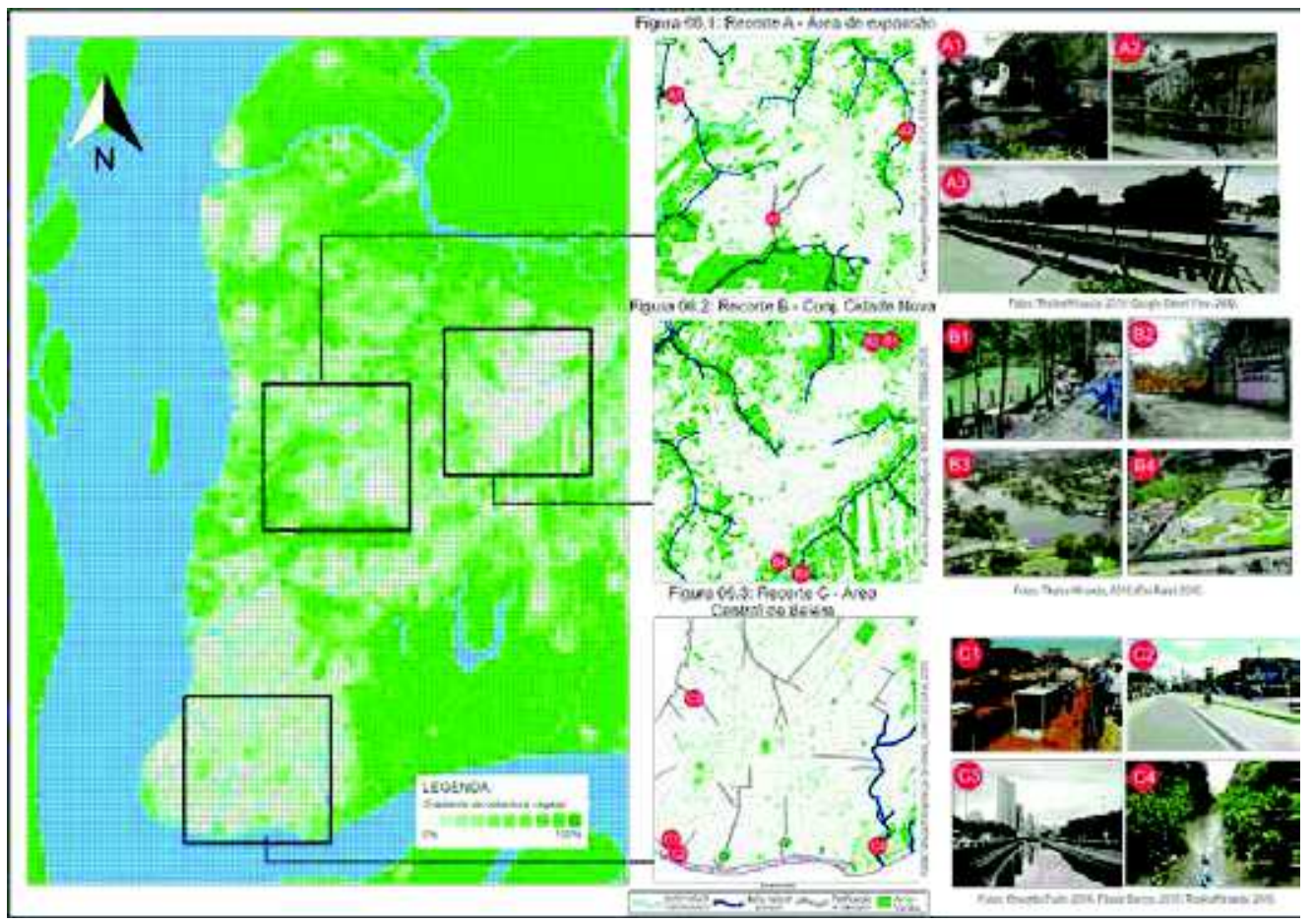

Figura 6 Mapa de gradiente da cobertura vegetal, associado aos rios urbanos, com recortes para diferentes áreas das cidades de Belém e Ananindeua. A figura 6.1 corresponde a área de expansão de Belém; a figura 6.2 ao conjunto habitacional Cidade Nova, em Ananindeua e a figura 6.3 a área central de Belém. Fonte: Imagem RapidEye do MMA, 2015. Elaboração: Patrick Rocha e Thales Miranda, 2017.

Na figura 6, o Recorte A captura parte da área de expansão de Belém. Observase a existência um padrão de diversidade de níveis de cobertura vegetal, com situações de maior concentração de verde próximo aos rios, e gradientes de supressão vegetal na direção dos empreendimentos habitacionais de produção mais recente (ver figura 6.1). Os cursos d'água foram poluídos conforme a ocupação se consolidava, processo agravado na década de 1990 pelas ocupações informais e pelo adensamento dos conjuntos habitacionais, inviabilizando definitivamente o uso tradicional dos rios (MIRANDA; CARDOSO, 2016). Além disso, desde 2008 essa área vem sofrendo transformações socioespaciais devido à capitalização do setor imobiliário nacional. Os mecanismos de financeirização viabilizaram grandes investimentos ao longo da Avenida Augusto Montenegro (principal eixo que estrutura a área), tornando-a alternativa nobre à produção de novas centralidades (VENTURA NETO, 2015). Os novos empreendimentos imobiliários (condomínios fechados horizontais e verticais) adensaram a área, diminuíram a permeabilidade do solo e passaram a lançar dejetos nos cursos d'água, que já não conseguem depurar o esgoto e garantir seu escoamento. As ocupações localizadas na proximidade dos muros construíram lajes sobre o rio, demonstrando uma alienação em relação à natureza que não existia até os anos 1970 (ROCHA, 2016). 
O Recorte B corresponde ao Conjunto Habitacional Cidade Nova, em Ananindeva, um dos maiores conjuntos produzidos pelo BNH. Destaca-se como a área de supressão da vegetação mais intensa da RMB. Com exceção das ruas principais, são poucas as ruas e espaços públicos arborizados e não há vegetação no "miolo" da quadra, como caso mais antigo, a situação da Cidade Nova antecipa as trajetórias mais prováveis em outros empreendimentos com padrões morfológicos semelhantes (dimensão de lotes, de ruas e quadras). Embora os projetos tenham previsto praças, a concepção desses espaços foi completamente diferente dos espaços nas margens de rios (balneários) onde acontecia a socialização e lazer dos grupos populares. É interessante notar a ocorrência de cursos d'água com leitos naturais e não poluídos na parte superior e inferior do recorte (ver figura 6.2). O curso d'água superior é localizado no bairro do Curuçambá (zona periurbana de Ananindeua) e ainda é utilizado pela população como balneário, porém de acesso privado. $\bigcirc$ outro está localizado dentro de condomínio horizontal fechado de alto padrão chamado de Lago Azul, que não permitiu que o sistema de esgotamento sanitário do conjunto vizinho fosse lançado próximo ao seu terreno, o que inviabilizaria a sua proposta de empreendimento (MIRANDA; CARDOSO, 2017).

O Recorte C: Corresponde à parte da área central de Belém, com produção formal segundo a lógica europeia de traçado regular de ruas e quadras, da hierarquia viária e supressão dos corpos d'água, para maximizar a possibilidade de ocupação. Observa-se que a maioria dos cursos d'água está retificada e polvída, e alguns já tamponados (ver figura 6.3). Essa lógica tende a ser seguida para outras áreas da cidade incorporadas pelo mercado formal, cuja provisão de infraestrutura segue o padrão hegemônico e simplifica espaços e modos de vida. Nessa lógica, as áreas vegetadas correspondem às principais avenidas ou praças, elementos paisagísticos da urbanização.

Observa-se que há uma tendência de urbanização não-compensatória em Belém e nos demais municípios da RMB, o que potencializa impactos negativos no âmbito ambiental e social. Substitui-se a multifuncionalidade dos rios urbanos (pesca, mobilidade, sociabilidade) pelo viés paisagístico, da natureza para contemplação. Conforme já informado por Cardoso, Miranda e Rocha (2016) enquanto os cursos d'água de pequeno porte são mortos pelo lançamento de esgoto in natura, os corpos d'água de maior porte, como os rios Maguari (na divisa entre os municípios de Belém e Ananindeua) e Benfica (no município de Benevides), têm recebido portos, marinas e festas, em que lanchas e jet-skis são utilizados para a prática de esporte e usufruto das águas por uma população de alta renda (ver figuras 7 e 8).

A supressão de vegetação e de cursos d'água não leva em conta que a recarga de aquíferos na RMB acontece por meio dos afloramentos (fontes e igarapés) de lençóis freáticos (CPRM, 2002). A opção pela proteção ambiental da porção sul da cidade, que corresponde à Unidade de Conservação Estadual (Decreto Estadual 
$n^{\circ}$. 1552/1993) e preparação do Parque Ambiental para oferta de atividades de lazer e contemplação, reforça o modo de pensar cosmopolita, que não reconhece a necessidade de parte da população que vive nas áreas mais baixas, mais pobre e mais vulnerável às enchentes, de acesso à terra, à água limpa e à biodiversidade, para melhorar suas condições de subsistência. $\bigcirc$ atendimento de necessidades de lazer, contemplação, prática esportiva da população é importante, mas o foco nessas funções não é suficiente nem do ponto de vista socioeconômico nem ambiental.

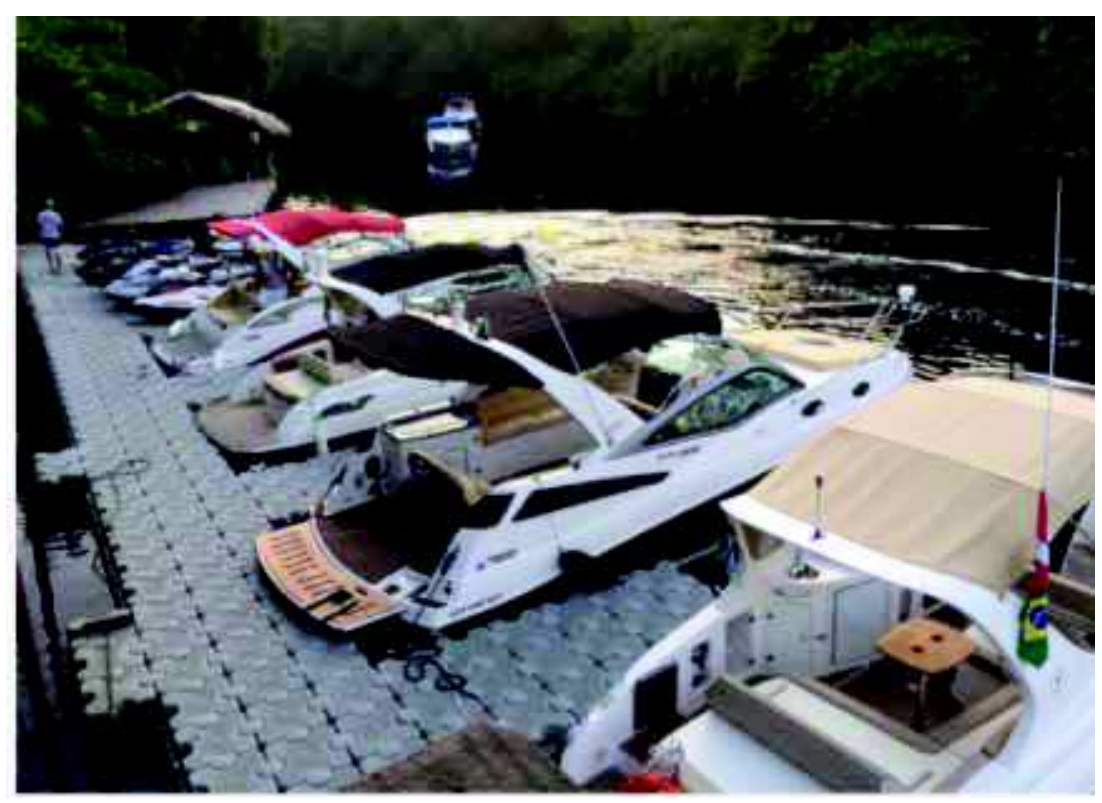

Figura 7 Foto da Marina Porto Seguro com lanchas e jet-skis atracados no Rio Maguari, divisa entre os municípios de Belém e Ananindeua.

Disponível em: <http://marinaportoseguro.com.br/MPS/Fotos.html\#16>. Acesso em 10 out. 2017.

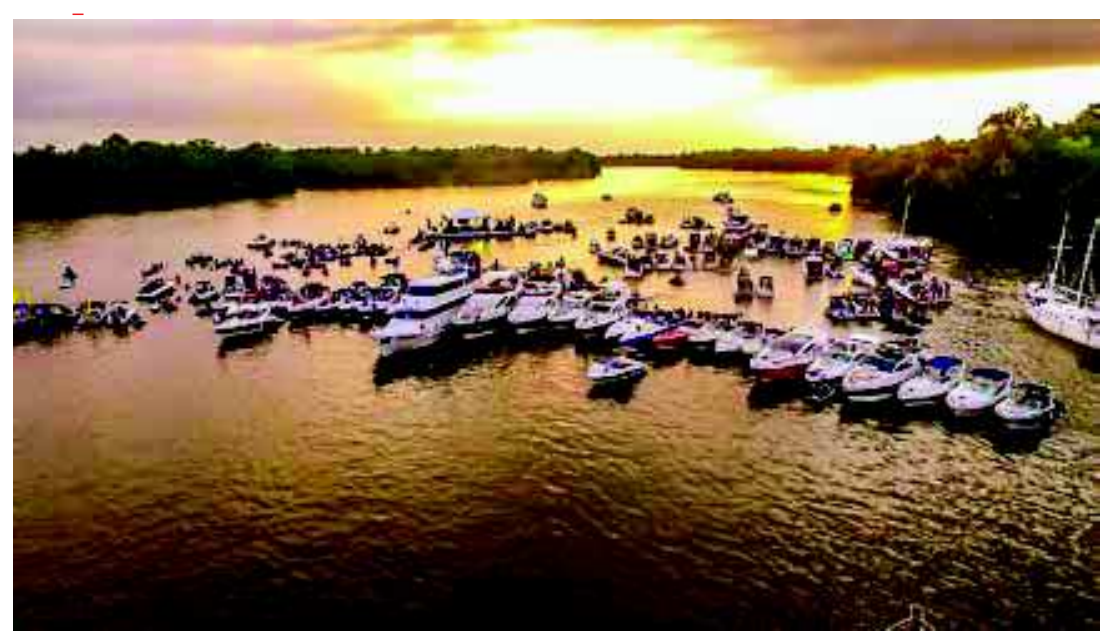

Figura $85^{\circ}$ Boat Party, festa realizada no rio Benfica, em Benevides.

Disponível em: <http://marinaportoseguro.com.br/MPS/Fotos.html\#43>. Acesso em 10 out. 2017. 
A esse respeito, as figuras $9,10,11,12,13$ e 14 oferecem evidência de que o avanço contínuo da mancha urbana, a redução da cobertura vegetal e o adensamento construtivo também estão ligados à alteração do microclima, no caso, com aumento de temperatura da cidade.

Para inferir alguma relação entre a supressão vegetal e a evolução das temperaturas na área correspondente aos municípios de Belém e Ananindeua, optou-se por partir da estimativa de temperatura de superfície via sensoriamento remoto, devido à comodidade do acesso à informação, uma vez que a aquisição direta da temperatura do ar (mais próxima da experiência sensível) dependeria do manuseio de um volume maior de informação e a uma complexidade de procedimentos que fogem ao escopo e à finalidade deste artigo.

Dessa forma, recorreu-se às imagens dos Satélites Landsat 5 e 8 disponibilizadas gratuitamente pelo site da United States Geological Survey - USGS (http://earthexplorer.usgs.gov/). Esses satélites possuem série temporal de 16 dias com passagem na linha do equador por volta das 10:00 horas, e permitem a extração da temperatura da superfície através de uma de suas bandas termais (banda 6 para o Landsat 5 e banda 10 para o Landsat 8), que permitem detecção de propriedades termais de rochas, solos, vegetação e água, com resolução espacial de 120 (Landsat 5) e 100 (Landsat 8) (PONTES et al, 2017). A limitação de horário dessa informação é compensada pela sua resolução espacial, permitindo uma interpretação na escala urbana, em contraposição ao sensor MODIS, que gera duas imagens ao dia, mas com resolução espacial de 1000 metros, inadequada para o espaço urbano. Procurou-se usar este recurso como indicação de evolução da temperatura no tempo, recorrendo as imagens com intervalo de cinco anos e adquiridas em dois momentos distintos, nos meses mais típicos das duas estações climáticas observadas na região amazônica: o período chuvoso (dezembro até maio) e o menos chuvoso (junho até novembro) (MOREIRA, 2018).

As figuras 9, 11 e 13 correspondem à estação chuvosa e datam de abril de 2006, janeiro de 2011 e fevereiro de 2016, respectivamente. As figuras 10, 12 e 14 correspondem à estação menos chuvosa e datam de agosto de 2006, setembro de 2011 e agosto de 2016, respectivamente.

Todas as imagens extraídas sofreram processos de correção atmosférica, uma vez que conforme Weiss et al $(2015$, p. 1) "a atmosfera afeta a radiância refletida pela superfície que é captada pelo sensor devido aos fenômenos de espalhamento, absorção e refração da energia eletromagnética". A correção das imagens Landsat 5 e 8 foi realizada segundo instruções de Coelho e Correa (2013) ao definir parâmetros fixos de conversão de níveis de cinza da imagem (NC) para radiância e depois para temperatura Kelvin, como demonstrado nas equações 2 e 3. 


$$
L_{\lambda}=M_{L} Q_{\mathrm{cal}}+A_{\mathrm{L}}
$$

Onde: $L \lambda$ : Radiância Espectral do sensor de abertura em Watts/( m2 sr $\mu \mathrm{m})$; ML: Fator multiplicativo de redimensionamento para banda 10 (Landsat 8) $=3.3420 \mathrm{E}$ 04 e para a banda 6 (Landsat 5) $=0.055$; AL: Fator de redimensionamento aditivo específico para banda $10=0.10000$ e para a banda $6=1.18243$; Qcal: Valor quantizado calibrado pelo pixel em $\mathrm{DN}=$ Imagem banda 10 e Imagem banda 6 .

Após a transformação dos valores em radiância da equação 2, aplicou-se a equação 3 nas imagens de satélites com a finalidade de transformar os valores obtidos da equação 2 em temperatura de valor em Kelvin, a qual foi subtraída pelo seu valor absoluto $(273,15)$, gerando imagens de temperatura de superfície em graus Celsius $\left({ }^{\circ} \mathrm{C}\right)$ (COELHO; CORREA, 2013).

$$
T=\frac{K_{2}}{\ln \left(\frac{K_{1}}{L_{2}}+1\right)}
$$

Onde: T: Temperatura efetiva no satélite em Kelvin (K); K2: Constante de calibração $2=1.321 .08(\mathrm{~K}) ; \mathrm{K} 1$ : Constante de calibração $1=774.89(\mathrm{~K})$; L $\lambda$ : Radiância espectral em Watts/(m2 sr $\mu \mathrm{m})$.
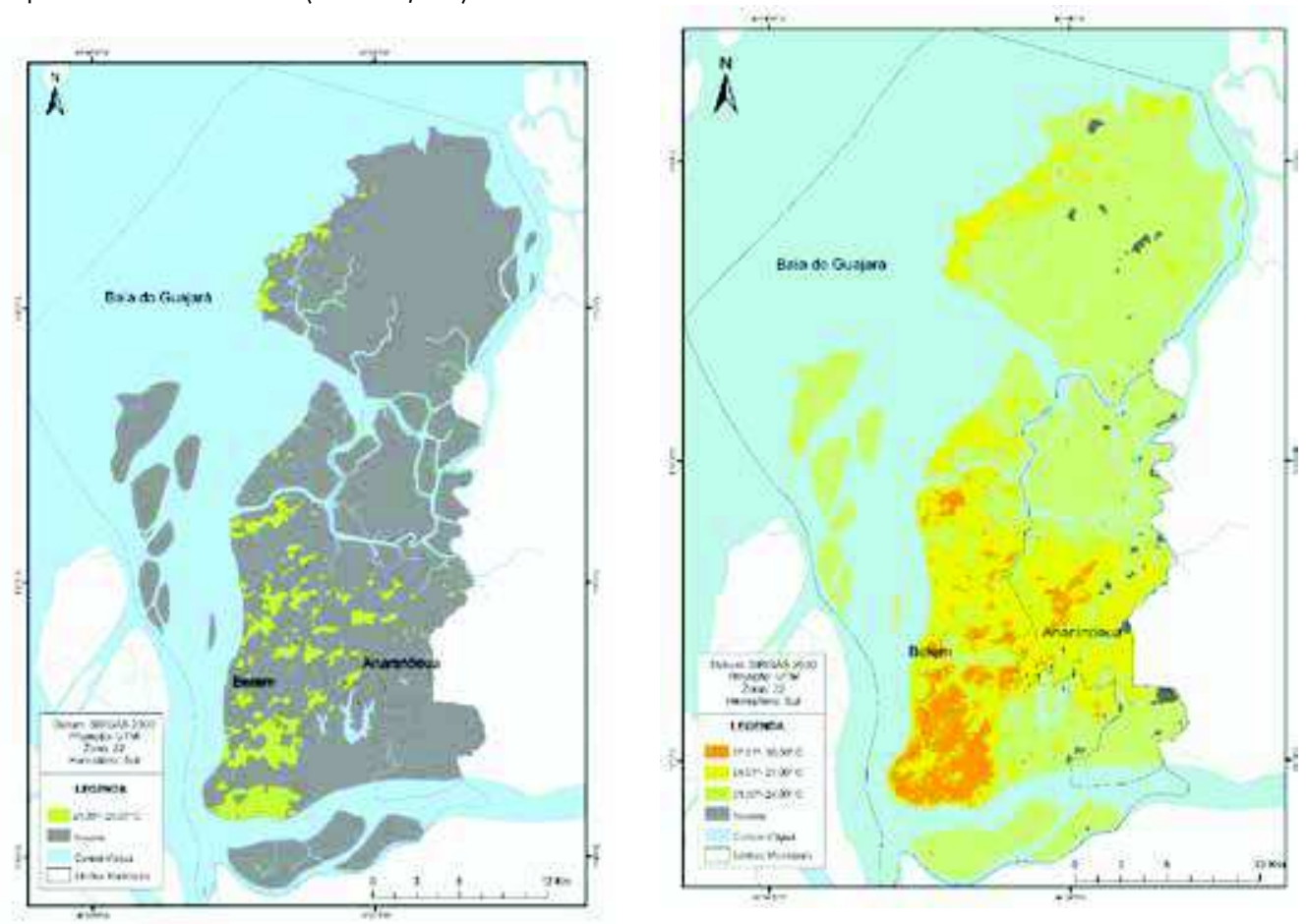

Figura 9 e 10 Temperatura da superfície para Belém e Ananindeua no ano de 2006 - LANDSAT 5 no dia 19 de abril de 2006 (período mais chuvoso) e 08 de agosto de 2006 (período menos chuvoso), respectivamente. Fonte: USGS, 2006. 

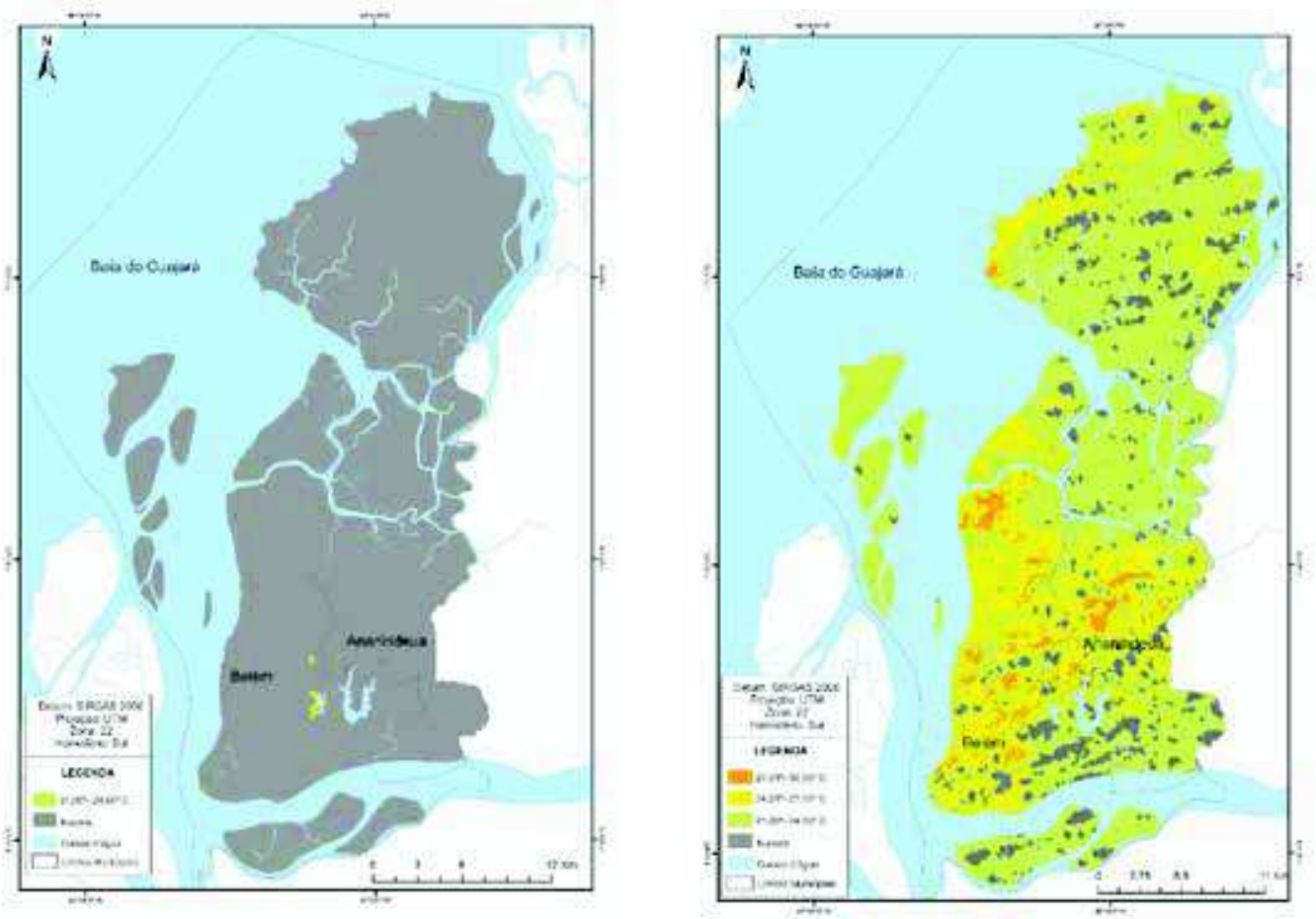

Figura 11 e 12 Temperatura da superfície para Belém e Ananindeua no ano de 2011 - LANDSAT 5 no dia 27 de janeiro de 2011 (período mais chuvoso) e 08 de setembro de 2011 (período menos chuvoso), respectivamente. Fonte: USGS, 2011.
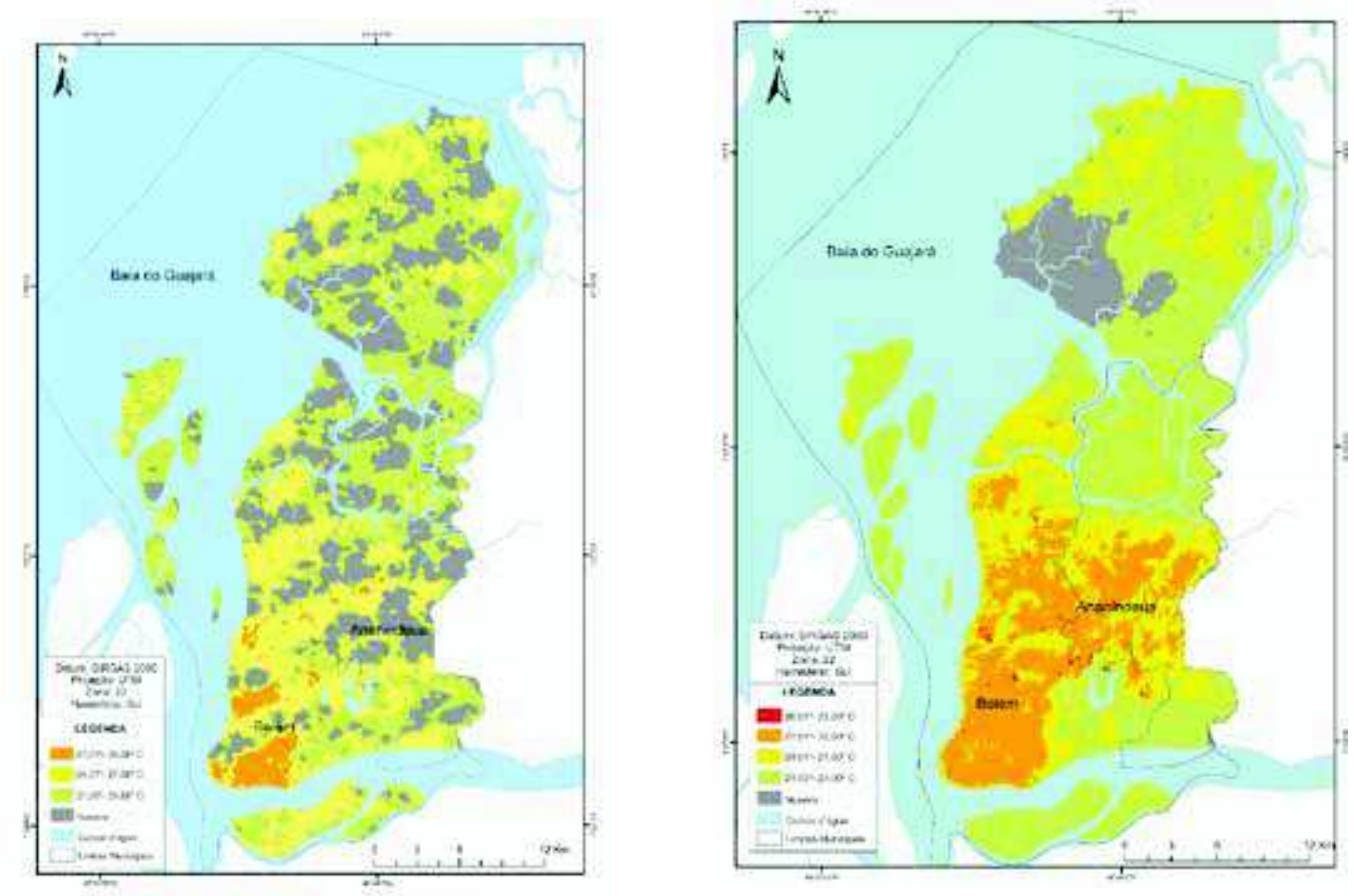

Figura 13 e 14 Temperatura da superfície para Belém e Ananindeua no ano de 2016 - LANDSAT 8 no dia 10 de fevereiro de 2016 (período mais chuvoso) e 06 de agosto de 2016 (período menos chuvoso), respectivamente. Fonte: USGS, 2016 
A partir de uma busca de dados para todos os anos do intervalo para os meses chuvosos, observou-se que os dados referentes à estação chuvosa são sempre severamente comprometidos pela presença de nuvens, inviabilizando análises conclusivas. Na figura 13, apesar da maior parte do território estar coberto por nuvens, há condições de análise dos dados de temperatura de superfície, que indicam que no centro de Belém as temperaturas ajustadas variariam entre $27^{\circ} \mathrm{C}$ a $30^{\circ} \mathrm{C}$, semelhante ao observado na estação menos chuvosa (verão local). Ressalta-se que para o ano de 2011 , a presença de nuvens distorce a temperatura, em relação ao observado nas imagens 10 e 14, onde há um padrão mais nítido de variação de temperatura na área consolidada.

A imagem apresentada na figura 14 para a estação menos chuvosa, evidencia uma tendência de elevação de temperatura nas áreas mais adensadas, onde ocorreu uma intensa supressão vegetal. Percebe-se que no ano de 2006 e 2011 a porção continental do território, que corresponde à mancha urbana mais consolidada, contava com temperaturas de superfície ajustadas entre $24^{\circ} \mathrm{C}$ e $27^{\circ} \mathrm{C}$. As temperaturas mais altas foram encontradas no Conjunto Habitacional Cidade Nova em Ananindeva, nas áreas verticalizadas do centro de Belém, nas baixadas consolidadas próximo ao centro, com temperatura de superfície ajustadas de até $30^{\circ} \mathrm{C}$. Em contraponto, temperaturas mais amenas, entre $21^{\circ} \mathrm{C}$ e $24^{\circ} \mathrm{C}$, caracterizavam o espaço das ilhas, e as áreas ocupadas com grandes massas vegetais na porção continental, que correspondem às áreas protegidas e aos parques.

Para 2016 (figura 14), observa-se que temperatura de superfície ajustada aumentou $3^{\circ} \mathrm{C}$ na mancha urbana mais consolidada, onde a temperatura dominante passou a ser $30^{\circ} \mathrm{C}$. Há, porém, salvaguardas para áreas arborizadas como cemitério Santa lzabel do Pará, Bosque Municipal Rodrigues Alves e algumas ruas arborizadas que mantiveram a temperatura máxima em até $27^{\circ} \mathrm{C}$, como observado para 2006 e 2011 . O curioso é o aumento de temperatura para $33^{\circ} \mathrm{C}$ em pontos isolados ao longo da Rodovia BR-316, no aeroporto internacional de Belém, nas áreas verticalizadas do centro e em alguns pontos da Área de Expansão onde predomina a ausência de cobertura vegetal nas vias públicas. As porções mais urbanizadas das ilhas conectadas ao continente por pontes sofreram um aumento de temperatura de $24^{\circ} \mathrm{C}$ em 2006 e 2011 para $27^{\circ} \mathrm{C}$ em 2016, enquanto as demais que não sofreram ações diretas da urbanização mantiveram o mesmo patamar de temperatura de superfície.

Não por acaso, a região insular de Belém e algumas áreas periurbanas do continente ainda mantém a cobertura vegetal, o que garante os mesmos níveis de temperatura, e desse modo consegue abastecer as feiras e mercados com produtos agrícolas e produtos extrativistas apreciados localmente (geralmente frutas) e garantir a produção familiar em áreas rurais e periurbanas de Belém, Ananindeua, Benevides, Santa Bárbara do Pará e Santa Izabel do Pará (municípios que compõem a Região Metropolitana). No entanto, há progressiva redução dos pequenos produtores fami- 
liares e extrativistas urbanos que ocupam esses espaços, além de pressão por alteração de uso pelo setor imobiliário mesmo nas ilhas, e avanço da produção rural de larga escala, que opera em áreas maiores, com uso de produtos químicos que degradam o meio ambiente, mas resultam em mercadorias mais baratas, o que acarreta uma concorrência desigual, quando comparamos o preço final dos produtos.

O imediatismo e a tendência à assimilação de políticas e práticas que priorizam o interesse econômico e a esfera privada, negligenciam a oportunidade que a Região Metropolitana de Belém tem de construir coletivamente uma trajetória própria, e de se aproximar, por exemplo, do cumprimento de recomendações dos 17 objetivos de desenvolvimento sustentável (ODS) da Organização das Nações Unidas (ONU) (ver figura 15) que devem ser implementados por todos os países do mundo até 2030 (ONUBR, 2017). A produção de alimentos garante a segurança alimentar, assegura padrões de produção e consumo sustentáveis, e resguarda áreas permeáveis e vegetadas que são manejadas pelas populações que praticam agricultura urbana e extrativismo, mas que também podem ser por outras espécies para manter o fluxo da vida (animais), podem ser usadas para caminhadas, acesso à natureza, sociabilidade, etc., sob supervisão dessas comunidades.

\section{(3) OBJETIV $\mathrm{S}_{\text {SUSTENTAVEL }}^{\text {or }}$}
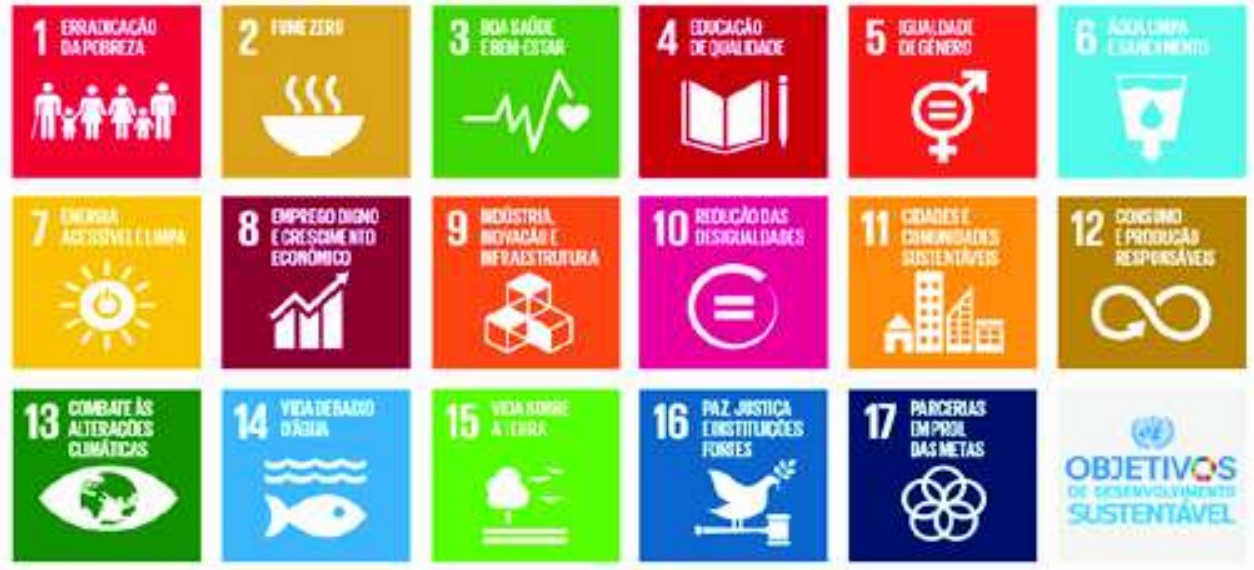

(4)

OBJETIVOS

SuSTEMAVE

Figura 15: Os 17 Objetivos de desenvolvimento sustentável. Fonte: ONUBR, 2015.

Por outro lado, as próprias comunidades não têm a compreensão da sua contribuição para: o desempenho ambiental e econômico da metrópole; o auxílio na redução da temperatura e dos alagamentos; a garantia de alimentos e oferta de trabalho para indivíduos que podem não ter escolaridade, mas tem conhecimento popular sobre como manejar a natureza. $O$ aprofundamento de pesquisa sobre 0 desdobramento desses processos a médio e longo prazo poderia alimentar um de- 
bate mais qualificado sobre o impacto da intervenção planejada (pública ou privada) nesses contextos, que via de regra aborda a realidade de uma perspectiva reduzida e simplificada.

\section{CONCLUSÃO}

A desvalorização do saber tradicional ligado ao manejo da terra e dos recursos naturais resulta na perda da identidade e na opção por trabalho desqualificado, sujeito aos baixos rendimentos e a um confinamento dos grupos sociais socialmente excluídos ao espaço da habitação, por insuficiência de renda para frequentar os espaços coletivos e as estruturas de lazer privadas. A informação das conexões entre desmatamento, impermeabilização do solo, adensamento construtivo, violência urbana, perda de resiliência ambiental e a degradação do patrimônio natural, poderia ampliar o debate sobre a garantia do acesso à terra urbanizada, que atualmente pressupõe que a infraestrutura técnica e a propriedade privada da terra sejam fundamentais para a vida das pessoas em ambiente urbano. Contudo, a pesquisa acumulada sobre a transformação das cidades da região (MIRANDA; CARDOSO, 2016; MELO, 2015; PONTES, 2015; GOMES, 2017) demonstra que, além da infraestrutura e equipamentos sociais, a base natural (terra, rios e vegetação) é elemento fundamental para a emancipação de grupos sociais que precisam dela para produzir e viver. Em sentido amplo, o reconhecimento de que há pluralidade, de pessoas ou grupos sociais, de formas de vida e espécies, será um primeiro passo de uma possível requalificação das RMB e para as cidades amazônicas, de importância cada vez mais estratégica em um contexto regional em que o espaço rural está a cada dia mais articulado a produção global e à exportação.

Percebe-se que a população tradicional, que depende da natureza para viver e que não necessariamente está vinculada a uma economia formal moderna, paulatinamente vem sendo expulsa de seus lugares de vida para sítios mais distantes, de modo a viabilizar a produção formal da cidade em antigas áreas de várzea cuja localização já é central. Esse fenômeno é aceito e fomentado como parte de um processo de expansão da mancha urbana que potencializa o lucro imobiliário pela possibilidade de acumulação primitiva, viabilizada pela conversão de áreas rurais ou de mata em terra urbana. Essa expansão trata o espaço da várzea como reserva de valor, visto que quando o estoque de terras altas se esgota, a pressão imobiliária é direcionada para as áreas de várzea consolidadas (aterradas e ocupadas). Esse padrão de operação reduz a cobertura vegetal nas áreas incorporadas pelo mercado e reinicia o processo em áreas cada vez mais distantes, em um círculo vicioso de expansão urbana, bastante perversa em ambiente amazônico.

Além disso, com exceção das ilhas, são poucas as áreas de produção de alimentos regionais na RMB. A lógica hegemônica desvaloriza a produção e o modo 
de vida tradicional e com isso tende a homogeneizar os espaços naturais. Contudo, observa-se que na periferia esse processo tende a ser mais impactante do que aquele ocorrido na área central de Belém (remoção de verde, contaminação de rios, impermeabilização do solo e de gentrificação), com agravamento dos impactos sociais e ambientais. $\bigcirc$ exemplo de Belém indica que as cidades amazônicas, onde sempre existiram grupos sociais que dependem da natureza para a sua sobrevivência, precisam reconhecer a pluralidade de sua população e a necessidade de formulação de políticas de territoriais, sociais e ambientais articuladas, de modo a colocar os interesses coletivos acima dos individuais, e a participação qualificada acima das estratégias de manipulação de massas. Criar mecanismos de respeito aos valores e cultura da população seria uma forma de inclusão social, de garantia de acesso à cidade, de manutenção da identidade evocada elo interesse turístico, mas ainda em franco processo de desvanecimento.

Agradecimento: Os autores agradecem as indicações dos avaliadores e a colaboração da Engenheira Sanitária e Ambiental e Mestre em Ciências Ambientais Fernanda da Silva de Andrade Moreira, na análise dos dados de sensoriamento remoto. Agradecem também as bolsas de Produtividade em Pesquisa e de Iniciação Científica, ambas concedidas pelo CNPq e a tradução de Brian Honeyball.

\section{REFERÊNCIAS BIBLIOGRÁFICAS}

ABELÉM, Auriléa Gomes. Urbanização e remoção: por que e para quem? . Belém: Centro de Filosofia e Ciências Humanas, NAEA, UFPA, 1988. 165 p.

ARAUJO, Gustavo Henrique de. Sousa. et al. Gestão ambiental de áreas degradadas. $3^{a}$ ed. 320p. Rio de Janeiro: Berrtrand Brasil, 2008.

BRASIL. Lei Complementar № 14, de 08 de Junho de 1973. Estabelece as Regiões Metropolitanas de São Paulo, Belo Horizonte, Porto Alegre, Recife, Salvador, Curitiba, Belém e Fortaleza. Brasil, 1973

BUENO, Laura Machado de Mello. A adaptação da cidade às mudanças climáticas: uma agenda de pesquisa e uma agenda política. In. OJIMA, R; MARANDOLA JR., E. Mudanças Climáticas e as Cidades: Novos e Antigos Debates na Busca da Sustentabilidade Urbana e Social. São Paulo: Blucher, 2013.

CARDOSO, Ana Claudia Duarte. The Alternative Space: informal settlements and life chances in Belém, Brazil. 2002.353 f. Thesis (PhD em Arquitetura). Oxford, Oxford Brookes University, 2002.

; FERNANDES, Danilo Araújo; BASTOS, Ana Paula Vidal. A inserção da RMB na Amazônia e na rede urbana brasileira. In. CARDOSO, A. C. D.; LIMA, J. J. F. (Orgs.). METRÓPOLES: Território, Coesão Social e governança Democrática. Belém: Transformações na ordem urbana. Rio de Janeiro: Letra Capital, 2015. p. 17-33

; MIRANDA, Thales Barroso; COSTA, Christiane Helen Godinho. Transformações Urbanas e Sócio Ambientais na Cidade de Belém: A Contramão Perversa. In: COLÓQUIO QUAPÁ-SEL, 11 ., 2016, Salvador. Anais Eletrônicos do XI COLÓQUI QUAPA-SEL. Salvador. 2016. p. 1-16.

; MIRANDA, Thales Barroso; ROCHA, Patrick da Costa. Da Degradação à Elitização: Processos de Exclusão Social e Ambiental em Belém. Revista Terceira Margem Amazônia. Belém, v. 2, nº 7 - Jul/dez. 2016. ; VENTURA NETO, Raul da Silva. A evolução urbana de Belém: trajetória de ambiguidades e conflitos socioambientais. Cadernos Metrópoles. São Paulo, v. 15, n. 29, p. 55-75, jan/jun 2013. http://dx.doi. org/10.1590/15816

RODRÍGUES, Alice. Uma janela para o reduto: estudo de renovação urbana. 1990. 122 f. Trabalho de Conclusão de Curso (Gradução) - Curso de Arquitetura e Urbanismo, Centro Tecnológico, Universidade Federal do Pará. Belém, 1990. 
CASTRO, Fábio Fonseca de. A cidade sebastiana: era da borracha, memória e melancolia numa capital da periferia da modernidade. Edições do autor. Belém, 2010.

COELHO, André Luiz Nascentes; CORREA, Wesley de Souza Campos. Temperatura de Superfície Celsius do Sensor Tirs/Landsat-8: Metodologia e Aplicações. Revista Geografia Acadêmica, v.7, n.1. 2013. http://dx.doi.org/10.18227/1678-7226rga.v7i1.2996

CORRÊA, Roberto Lobato. A periodização da rede urbana da Amazônia. Revista Brasileira de Geografia, Rio de Janeiro, v. 4, n.3, p. 39-68, jul./set. 1987

COSTA, Francisco de Assis, FERNANDES, Danilo Araújo. Dinâmica agrária, instituições e governança territorial para o desenvolvimento sustentável da Amazônia. Revista de Economia Contemporânea (Impresso), v. 20, p. 517-518, 2016. http://dx.doi.org/10.1590/198055272036.

CPRM. Projeto Estudos Hidrogeológicos da Região Metropolitana de Belém e Adjacências. Brasília: Ministério de Minas e Energia, 2002. 101 p.

GITELSON, A.A., AND M.N. MERZLYAK. Quantitative estimation of chlorophyll-a using reflectance spectra: Experiments with autumn chestnut and maple leaves. Journal of Photochemistry and Photobiology, B: Biology. v. 22, n. 3, p. 247-252, 1994.

GOMES, Taynara do Vale. Santarém: uma articulação possivel entre urbanização e natureza. 94 f. Dissertação (Mestrado em Arquitetura e Urbanismo) - Programa de Pós-Graduação em Arquitetura e Urbanismo, Universidade Federal do Pará, Belém. 2017.

HECKENBERGER, Michael. The Ecology of Power: Culture, Place, and Personhood in the Southern Amazon, A.D. 10002000, New York and London, Routledge, 2005, 404 p.

IBGE, 2010. Censo Demográfico. Resultados do Universo. Disponível em: <http://www.ibge.gov.br>. Acesso em: fev. 2018.

IBGE, 2014. Produto Interno Bruto de Santa Izabel do Pará. Disponível em<http://cidades.ibge.gov.br/xtras/ temas. php? lang $=\&$ codmun $=150650 \&$ idtema $=162 \&$ search $=$ para $\mid$ santa-izabel-do-para $\mid$ produto-interno-brutodos-municipios-2014>. Acesso em: set. 2017

LEFÈBVRE, Henri. A revolução urbana. Belo Horizonte: Editora UFMG, 1999. 178 p.

LIMA, José Júlio Ferreira. et al. Estrutura Social e Organização Social da Região Metropolitana de Belém. In. CARDOSO, A. C. D.; LIMA, J. J. F. (Orgs.). Metrópoles: Território, Coesão Social e governança Democrática. Belém: Transformações na ordem urbana. Rio de Janeiro: Letra Capital, 2015. P. 145-172

LIMONAD, Ester. A insustentável natureza da sustentabilidade. Da ambientalização do planejamento às cidades sustentáveis. Cadernos Metrópole. São Paulo: EDUC, n 29, v 15, p. 123-142, 2013. http://dx.doi.org/10.1590/15819 MARICATO, Ermínia. Para Entender a Crise Urbana. São Paulo: Expressão Popular, 2015. 112 p.

MELO, Ana Carolina Campos. Modernização e Transformações Recentes nos Processos Intra-Urbanos no Sudeste do Pará. 141 f. Dissertação (Mestrado em Arquitetura e Urbanismo) - Programa de Pós-Graduação em Arquitetura e Urbanismo, Universidade Federal do Pará, Belém. 2015.

MIRANDA, Thales Barroso; CARDOSO, Ana Claudia Duarte. Cartografias de invisibilidades na periferia metropolitana de Belém: estudo de padrões espaciais e relacionamentos da população com espaços públicos/ verdes. Relatório Final PIBIC, Universidade Federal do Pará, Belém, 21 p. 2017

Compreendendo o espaço público da área de expansão de Belém a partir de cartografias e análises morfológicas. Relatório Final PIBIC, Universidade Federal do Pará, Belém, 20p. 2016

MOREIRA, Fernanda da Silva de Andrade. Análise Socioambiental do Município de Belém, Pará: Elementos Para Uma Sustentabilidade Urbana. 137 f. Dissertação (Mestrado em Ciências Ambientais) - Programa de Pós-Graduação em Ciências Ambientais, Universidade Federal do Pará, Belém. 2018.

MOURÃO, Leila. O conflito fundiário urbano em Belém (1960-1980): a luta pela terra de morar ou de especular. 1987. 148 f. Dissertação (Mestrado) - Curso de Mestrado em Planejamento do Desenvolvimento, Núcleo de Altos Estudos Amazônicos, Universidade Federal do Pará. Belém, 1987.

ONUBR. Conheça os novos 17 Objetivos de Desenvolvimento Sustentável da ONU. 2015. Disponível em: <https://nacoesunidas.org/conheca-os-novos-17-objetivos-de-desenvolvimento-sustentavel-da-onu/>. Acesso em: 11 ago. 2017.

PONTES, Ana Karla dos Santos; SILVA, Paulo Vinícius Caldas da; SANTOS, Joyse Tatiane Souza dos; SOUSA, Adriano Marlisom Leão de. Temperatura em superfície urbanas usando sensor TIRS-Landsat 5 e 8: estudo de caso em BelémPA. Revista Brasileira de Iniciação Científica, Itapetininga, v. 4, n. 9, p.118-132. 2017

PONTES, Louise Barbalho. Cidade, desenho e natureza: uma reflexão sobre os espaços livres de Marabá. 2015. 127 f. Dissertação (Mestrado em Arquitetura e Urbanismo) - Programa de Pós-Graduação em Arquitetura e Urbanismo, Universidade Federal do Pará, Belém. 2015. 
RIBEIRO. Luiz César de Queiroz (Org.). Metrópoles: entre a coesão e a fragmentação, a cooperação e o conflito. 2. ed. Rio de Janeiro: Letra Capital, Observatório das Metrópoles, 2004

ROCHA, Patrick Costa. Proposta de Requalificação Urbana e Ambiental: As Margens do Rio Ariri. 2016. 87p. Trabalho de Conclusão de Curso. Universidade Federal do Pará. Belém, 2016.

SANTOS, Beatriz Luiza Leal Fiock dos; CARDOSO, Ana Claudia Duarte. Tendências morfológicas, sociais e ambientais na periferia urbana de Belém do Pará. Relatório Final PIBIC, Universidade Federal do Pará, Belém, 20p. 2015

SARGES, Maria de Nazaré dos Santos. Memórias do velho intendente Antônio Lemos (1869-1973). Belém: Paka-Tatu, 2004.

SOUZA, Carlos Henrique Wachholz de; LAMPARELLI, Rubens; JUSTINA, Diego Della; ROCHA, Jansle Vieira. Estudo da Banda Red Edge do satélite Rapideye na discriminação da cobertura vegetal. In: SIMPÓSIO BRASILEIRO DE SENSORIAMENTO REMOTO, 17., 2015, João Pessoa. Anais Eletrônicos do XVII Simpósio Brasileiro de Sensoriamento Remoto. João Pessoa, 2015, p. 1-6.

SOUZA, Renata Durans Pessoa. Área de Expansão de Belém: Um espaço de múltiplas vivências. 2016.155 f. Dissertação (Mestrado em Arquitetura e Urbanismo) - Programa de Pós-Graduação em Arquitetura e Urbanismo, Universidade Federal do Pará, Belém. 2016.

TAVARES, Hermes. Políticas de desenvolvimento regional nos países do "centro" e no Brasil. Cadernos IPPUR/UFRJ. Rio de Janeiro, Ano 1, n. 1, jan./abr. 1986

TONUCCI FILHO, João Bosco Moura. et al. Estrutura produtiva e mercado de trabalho na Região Metropolitana de Belo Horizonte: formação histórica e perspectivas contemporâneas. In. ANDRADE, L.T.; MENDONÇA, J. G.; DINIZ, A. M. A.; (Orgs.). Metrópoles: Território, Coesão Social e governança Democrática. Belo Horizonte: Transformações na ordem urbana. Rio de Janeiro: Letra Capital, 2015. p. 49-88.

TRINDADE JR., Saint-Clair Cordeiro da. A Cidade Dispersa: os novos espaços de Assentamentos em Belém e a Reestruturação Metropolitana. 1998. 395 f. Tese (Doutorado em Geografia) - Universidade de São Paulo, Faculdade de Filosofia, Letras e Ciências Humanas. São Paulo, 1998.

USGS (United States Geological Service). Earth Explorer. LANDSAT 5. Washington/DC: USGS, abr. 2006. [Imagem digital de satélite.] Disponível em: <https://earthexplorer.usgs.gov>. Acesso em: 09 Fev. 2018.

USGS (United States Geological Service). Earth Explorer. LANDSAT 5. Washington/DC: USGS, ago. 2006. [Imagem digital de satélite.] Disponível em: <https://earthexplorer.usgs.gov>. Acesso em: 15 out. 2017.

USGS (United States Geological Service). Earth Explorer. LANDSAT 5. Washington/DC: USGS, jan. 2011 . [Imagem digital de satélite.] Disponível em: <https://earthexplorer.usgs.gov>. Acesso em: 09 Fev. 2018.

USGS (United States Geological Service). Earth Explorer. LANDSAT 5. Washington/DC: USGS, set. 2011 . [Imagem digital de satélite.] Disponível em: <https://earthexplorer.usgs.gov>. Acesso em: 10 Fev. 2018.

USGS (United States Geological Service). Earth Explorer. LANDSAT 8. Washington/DC: USGS, fev. 2016. [Imagem digital de satélite.] Disponível em: <https://earthexplorer.usgs.gov>. Acesso em: 10 Fev. 2018.

USGS (United States Geological Service). Earth Explorer. LANDSAT 8. Washington/DC: USGS, ago. 2016. [Imagem digital de satélite.] Disponível em: <https://earthexplorer.usgs.gov>. Acesso em: 15 Out. 2017.

VENTURA NETO, R. Belém e o imobiliário: uma cidade entre contratempos e contradições. Belém: Imprensa Oficial do Estado, 2015.

VILLAÇA, Flávio. O Espaço intra-urbano no Brasil. São Paulo: Studio Nobre, 1998. 373 p.

WEISS, Carlos Vinicius da Cruz; CAMARGO, Diego Coelho da Silva; ROSCA, Eduardo Henrique; ESPINOZA, Jean. Análise comparativa entre métodos de correção atmosférica em imagens do sensor Operational Land Imager (OLI), plataforma Landsat 8. Scientia Plena, v. 11, n. 2, 2015. 
